\title{
Pediculosis capitis among primary-school children in Mafraq Governorate, Jordan
}

M. AlBashtawy and F. Hasna ${ }^{2}$

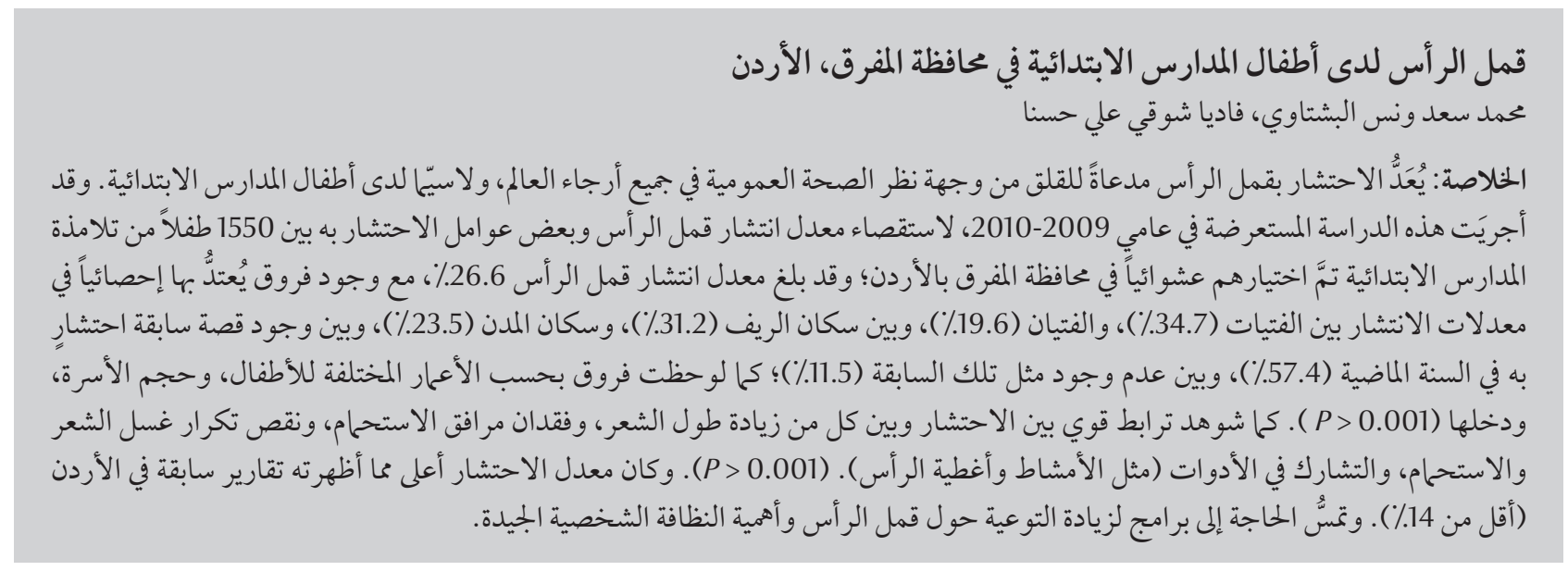

ABSTRACT Pediculosis capitis (head lice infestation) is a worldwide public health concern affecting mostly primary-school children. In a cross-sectional study in 2009/2010, the prevalence of pediculosis capitis and some risk factors for infestation were investigated among 1550 randomly selected primary-school children in Mafraq governorate, Jordan. The prevalence of pediculosis capitis was $26.6 \%$. There were significant differences in the prevalence between girls (34.7\%) and boys $(19.6 \%)$, rural $(31.2 \%)$ and urban $(23.5 \%)$ residents, and history of infestation in the previous year (57.4\%) versus no history (11.5\%), as well as between children of different ages, family size and income $(P<0.001)$. Longer hair length, lack of bathing facilities, low frequency of hair-washing and bathing, and sharing of articles (e.g. combs, scarves) were significantly associated with infestation $(P<0.001)$. The prevalence of infestation was higher than reported in previous studies in Jordan $(<14 \%)$. Programmes are needed to increase awareness of pediculosis capitis and the importance of good personal hygiene.

\section{Pédiculose de la tête chez des écoliers du primaire dans le gouvernorat de Mafraq (Jordanie)}

RÉSUMÉ La pédiculose de la tête (infestation de la chevelure par des poux) est une préoccupation de santé publique mondiale affectant principalement les écoliers du primaire. Dans une étude transversale réalisée en 2009-2010, la prévalence de la pédiculose de la tête et certains facteurs de risque de l'infestation ont été évalués auprès de 1550 écoliers du primaire sélectionnés aléatoirement dans le gouvernorat de Mafraq (Jordanie). La prévalence de la pédiculose de la tête était de 26,6 \% globalement, mais des différences significatives ont été observées entre les filles $(34,7 \%)$ et les garçons $(19,6 \%)$, entre les habitants des zones rurales $(31,2 \%)$ et des zones urbaines $(23,5 \%)$ et entre ceux ayant des antécédents d'infestation dans les douze derniers mois $(57,4 \%)$ et les autres $(11,5 \%)$, ainsi qu'entre les enfants en fonction de leur âge, de la taille de la famille et du revenu $(P<0,001)$. Avoir les cheveux longs, ne pas disposer d'une salle de bain, ne pas se laver les cheveux ni se doucher souvent, et partager des objets comme les peignes et les écharpes étaient des facteurs fortement associés à une infestation $(\mathrm{P}<0,001)$. La prévalence de l'infestation était supérieure à celle rapportée dans les précédentes études effectuées en Jordanie (moins de $14 \%$ ). Des programmes sont nécessaires pour sensibiliser à la pédiculose de la tête et à l'importance d'une bonne hygiène personnelle. 


\section{Introduction}

Pediculosis capitis infestation, commonly known as head lice, is the manifestation of the obligate ectoparasite, Pediculus humanus capitis, which only affects the human scalp. It is an extremely contagious condition and most common among young children aged 3 to 12 years. It is a worldwide community health problem that affects children in both developed and developing countries [1-3].

Primary-school children aged 6-12 years are most at risk, although adults and children of other ages who have direct or indirect contact with primary-school children are also susceptible [4].

The pattern and prevalence of pediculosis capitis is dependent on many sociodemographic and economic factors such as overcrowding, hair characteristics and poor hygiene $[5,6]$. Lice infestation may lead to psychological distress and may disrupt learning performance of the children because of the social stigma associated with it $[2,3,7,8]$.

In Jordan, a few studies have been done among schoolchildren. One conducted in Amman (the capital of the country) showed that the prevalence of pediculosis was 11\% (1999) [7]. Another conducted in northern Jordan reported a prevalence of $13.4 \%$ and that socioeconomic factors were a significant factor in prevalence [8]. However, there are no published data available about the prevalence of head lice in Mafraq governorate in northern Jordan.

Therefore this study was undertaken to determine the prevalence and distribution of Pediculosis humanus capitis among primary-school children in Mafraq governorate, northern Jordan, and to identify the factors affecting the prevalence.

\section{Methods}

\section{Place of study}

This study was carried out in Mafraq governorate from December 2009 to February 2010. Mafraq governorate has a population of 265000 with a density of 9.9 per $\mathrm{km}^{2}$. It is the second largest governorate in the country, but has the second lowest population density. The total number of children aged 6-11 years enrolled in primary schools at the time of the study was 36124 . Permission to conduct the study was obtained from the Directorate of Education of the Mafraq Governorate (Ministry of Education).

\section{Study design and sample}

This was a school-based analytical crosssectional study carried out from December 2009 to February 2010. Students were selected from those enrolled in 394 primary schools in Mafraq governorate.

The sample size was estimated by using the following formula: $n=\left[z^{2}\right.$ $-p(1-p)] / \mathrm{e}^{2}$ where $n=$ sample size, $z=$ is the confidence level at $95 \%, p=$ expected prevalence $(0.5 \%)$ and $e=$ precision (margin of error at $5 \%$ ). Based on this formula, the minimum sample size needed was 385 students; however, the sample size was increased to include all eligible students in the selected schools so as to increase the power and validity of the study.

A total of 8 schools were randomly selected comprising 1638 eligible students in Grades 1 to 6. Four schools from which 932 students were enrolled were located in urban areas (Mafraq city) and 4 schools from which 618 children were enrolled were located in rural areas (Bedouin community) of the Mafraq Governorate.

\section{Data collection}

Data were collected by 5 nursing inspectors who had a bachelor degree in nursing and were trained to do hair examinations.
A day ahead of the examination date, 1638 consent forms were distributed for the children's parents to complete and sign. However we obtained approval from 1550 parents, a response rate of $94.6 \%$.

A suitable room was chosen in every selected school to conduct the hair examination. A detailed questionnaire was completed by the children with the help of the nurses and data on the following variables were recorded: sex, age, place of residence, family size, mothers' employment, family income in Jordanian dinars (JD), bathing facilities, frequency of hair washing, frequency of bathing, sharing of articles in contact with hair (e.g. combs, scarves, pillows etc.) and lice infestations in the past year. Then hair was examined for head lice, as well as for eggs/nits, by full head examination, parting the hair every $3 \mathrm{~cm}$. The scalp was examined for 3-5 minutes with the naked eye, sometimes with the use of a hand lens and a fine-toothed comb. A child was considered infested if lice or eggs/nits were found either live or dead.

\section{Analysis}

Data entry and analysis were conducted using SPSS, version 16 software. The chi-squared test was used compare differences in proportions for the variables included. $P<0.05$ was considered statistically significant.

\section{Results}

Of the 1550 children included in the study, 832 were boys and 718 girls. The overall prevalence of pediculosis capitis among the 1550 schoolchildren was $26.6 \%$ (Table 1). The prevalence of infestation was significantly higher among girls (34.7\%) than boys (19.6\%), children with longer hair, those aged 6-8 years, rural rather than urban residents, those living with more than 10 family members (although only 5\% lived in such large families), those living in 


\begin{tabular}{|c|c|c|c|c|}
\hline Characteristic & No. of examinations & No. of infestation & Prevalence (\%) & $P$-value \\
\hline Sex & & & & $<0.0001$ \\
\hline Male & 832 & 163 & 19.6 & \\
\hline Female & 718 & 249 & 34.7 & \\
\hline Hair length & & & & $<0.0001$ \\
\hline Short, $<3 \mathrm{~cm}$ & 582 & 69 & 11.9 & \\
\hline Medium, $>3 \mathrm{~cm}$ to shoulder level & 529 & 173 & 32.7 & \\
\hline Long, > shoulder level & 439 & 170 & 38.7 & \\
\hline Age (years) & & & & $<0.0001$ \\
\hline 6 & 187 & 75 & 40.1 & \\
\hline 7 & 190 & 79 & 41.6 & \\
\hline 8 & 210 & 59 & 28.1 & \\
\hline 9 & 250 & 68 & 27.2 & \\
\hline 10 & 286 & 33 & 11.5 & \\
\hline $11+$ & 427 & 98 & 23.0 & \\
\hline Place of residence & & & & $<0.001$ \\
\hline Urban & 932 & 219 & 23.5 & \\
\hline Rural & 618 & 193 & 31.2 & \\
\hline Family size (No. of members) & & & & $<0.0001$ \\
\hline$<5$ & 370 & 35 & 9.5 & \\
\hline $5-10$ & 1101 & 342 & 31.1 & \\
\hline$>10$ & 79 & 35 & 44.3 & \\
\hline Family income (Jordanian dinars) & & & & $<0.0001$ \\
\hline$<200$ & 352 & 190 & 54.0 & \\
\hline $200-500$ & 726 & 179 & 24.7 & \\
\hline$>500$ & 472 & 43 & 9.1 & \\
\hline Mother's employment & & & & 0.204 \\
\hline Employed outside the home & 343 & 82 & 23.9 & \\
\hline Not employed outside the home & 1207 & 330 & 27.3 & \\
\hline History of infestation & & & & $<0.0001$ \\
\hline Yes & 509 & 292 & 57.4 & \\
\hline No & 1041 & 120 & 11.5 & \\
\hline Total & 1550 & & & \\
\hline
\end{tabular}

families with a monthly family income of $<200 \mathrm{JD}$, and those with a history of infestation in the previous year $(P<$ 0.0001 for all). Mother's employment status was not significantly associated with lice infestation. The highest percentage of pediculosis infestation was among children with a past history of infestation (57.4) and this was a statistically significant finding $(P<0.0001)$.

Table 2 shows the hygiene practices among schoolchildren and the association with lice infestation. The prevalence of head lice infestation was significantly higher (51.1\%) among children with no bathing facilities in their houses than those with such facilities (21.6\%) (P $<0.0001)$. Moreover, the prevalence of the infestation was significantly associated with the frequency of both hair washing $(50.5 \%$ among those washing hair $\leq 1$ time per week compared with $16.9 \%$ among those washing hair $\geq 3$ times per week) and bathing ( $42.8 \%$ among those bathing $\leq 1$ time per week compared with $15.7 \%$ among those bathing $\geq 3$ times per week) ( $P$ $<0.0001$ for both). In addition, the frequency of lice infestation was significantly higher among children who shared articles such as combs, scarves and towels among the family (38.2\%) compared with children who did not share $(17.2 \%)(P<0.0001)$.

\section{Discussion}

The prevalence of infestation with Pediculus humanus capitis in our study was $26.6 \%$, indicating it is a common condition among our primary-school 


\begin{tabular}{|c|c|c|c|c|}
\hline Hygiene practice & No. of examinations & No. of infestations & Prevalence (\%) & $P$-value \\
\hline \multicolumn{5}{|c|}{ Bathing facilities in the house } \\
\hline Yes & 1288 & 278 & 21.6 & \multirow[t]{2}{*}{$<0.0001$} \\
\hline No & 262 & 134 & 51.1 & \\
\hline \multicolumn{5}{|c|}{ Frequency of hair washing per week } \\
\hline$\leq 1$ time & 374 & 189 & 50.5 & \multirow{3}{*}{$<0.0001$} \\
\hline 2 times & 680 & 139 & 20.4 & \\
\hline$\geq 3$ times & 496 & 84 & 16.9 & \\
\hline \multicolumn{5}{|c|}{ Frequency of bathing per week } \\
\hline$\leq 1$ time & 472 & 202 & 42.8 & \multirow{3}{*}{$<0.0001$} \\
\hline 2 times & 702 & 151 & 21.5 & \\
\hline$\geq 3$ times & 376 & 59 & 15.7 & \\
\hline \multicolumn{5}{|l|}{ Sharing articles ${ }^{a}$} \\
\hline Yes & 693 & 265 & 38.2 & \multirow[t]{2}{*}{$<0.0001$} \\
\hline No & 857 & 147 & 17.2 & \\
\hline
\end{tabular}

${ }^{a}$ Combs, towels and clothes.

children. This figure is higher than previously reported in other areas in Jordan (Amman, North Jordan) (11.01\% and $13.4 \%$ respectively) $[7,8]$. There may be a number of likely explanations for this difference, including lifestyle and environmental issues because water is scarce in the remote areas of the Mafraq governorate in comparison to other rural areas in Jordan, and some of the children come from these remote areas. Furthermore, the surveys were conducted around 10 years before our study, during different seasons and in different governorates with different socioeconomic status and lifestyles. Mafraq Governorate still includes a Bedouin population with a nomadic lifestyle who are only semi-settled.

The rates of lice infestation among schoolchildren vary quite considerably across the world ranging from $5 \%$ to $78 \%[9,10]$. Furthermore, there has been a reported increase in worldwide pediculosis prevalence since 1965 [11].

Our figure is similar to some studies in different parts of the world $20.3 \%$ in Turkey [12], 21.9\% and $28.3 \%$ in the United Kingdom [13]. It is lower than the rates observed in other countries, 61.4\% in Argentina [14] and 35.5\% in Malaysia [15]. However, it is higher than that detected in other Middle Eastern countries, for example Egypt (5.5\%) [16], Turkey (5.1\%) [17], Palestine [10], Islamic Republic of Iran (1.8\%) [1] and Saudi Arabia (5.2\%) [18]. In Jordan, as in other Arab and Islamic countries, the most serious social consequence facing affected schoolchildren is social stigma $[1,2]$.

The prevalence of lice infestation in our study was significantly higher among girls than boys, which concurs with the results of other studies done in Jordan [8], the region $[1,2]$ and worldwide $[11,19]$. This higher infestation rate among girls can be explained by the difference in hair length, which we showed to be significantly associated with infestation, longer hair increasing the likelihood of infestation. Girls generally have longer hair than boys and also exhibit different behaviour to boys: boys have brief contact during daily playing and sporting activities, while girls tend to have closer, prolonged head contact in small groups $[1,20]$. Another important cultural factor is that a very high percentage of the girls in Mafraq Governorate wore a head cover because of their Islamic tradition. While covering the head might reduce the transmission of head lice by reducing hair contact between girls, at the same time covering the head may increase the prevalence of infestation of head lice by raising the scalp temperature and creating greater humidity $[1,2]$. Furthermore, many Jordanian girls cover their head only outside their home, and therefore transmission can still occur inside the home with their siblings and family members. Moreover, girls often exchange their head scarf with each other which may increase the chances of cross-infestation. The prevalence of lice infestation was very high among those children with long hair as it is more difficult to comb and keep clean it in comparison with short hair. In addition, school policies of enforcement of short hair-cuts among boys are likely to reduce transmission of the parasite.

In agreement with international trends, children aged 6-8 years were the most frequently affected with head lice $[1,2,4,7]$. This can be explained by behavioural factors whereby children at this age have more direct physical contact with each other. Furthermore, the degree of close contact with friends and family at this age might affect the infestation rate and this contact may decrease as children get older. 
Factors that may explain the higher prevalence in the rural areas of the Mafraq Governorate might be attributed to poor personal hygiene among family members because of scarcity of water resources and the semi-nomadic lifestyle, relative difficulty in accessing health services for treatment, and lack of knowledge of basic skin care. Some researchers maintain that lice infestation is found in all socioeconomic classes $[11,19]$, while others have reported that lice infestation is more common in rural areas among lower socioeconomic classes $[21,22]$. It has been reported in the literature that extreme poverty and overcrowded dwellings are closely related to poor hygiene practices and less concern about head lice infestation [23]. Our study agrees with this finding as our results showed that there were higher infestation rates among schoolchildren with family size $>10$ and lower family income $(<200$ JD). This may be because children from larger families with less income may not be able to pay attention to hair care and have a higher risk of the parasite being transmitted by their siblings [24].

Kokturk et al. [11] suggested that there was no significant association between head lice infestation and poor hygiene, while according to Mumcuoglu and Miller [25] better hygiene is the key to pediculosis control among well-off families. Our findings are more in agreement with Mumcuoglu and Miller, who found a strong correlation between lice infestation and the presence of bathing facilities in the home as well as the frequency of hair washing. This reinforces the importance of hair care (washing and brushing) and the frequency of hygiene practices in the prevention of lice infestation. Our findings showed that using shared articles including clothing (hats, scarves, veils), hair care items and accessories (combs, hair brushes, head ribbons) and sleep items (pillows and bed linen) increased the prevalence of head lice; this is in agreement with Heukelbach and Feldmeier [26].

Our study has some limitations. The schoolchildren that answered the questionnaires were enrolled in Grades 1 to 6: theiryoung ages as well as the variation in their age might have resulted in some inaccuracies in their answers. This factor could not be controlled and reflected actual students' perception. In addition, resources were not available to come up with an educational intervention to change students' behaviour with respect to hair hygiene and personal hygiene; we were therefore not able to compare infestation rates before and after such an intervention. Some incidental education was done by the nurses after examination for the infested students.
This is the first community-based study of the prevalence of pediculosis in Mafraq Governorate, which shows a high prevalence of lice infestation which can be explained by the abovementioned factors. Although educational campaigns by community health nurses and other health-care workers and teachers are expected to be helpful for head lice control, there remains the challenge of scarcity of resources and providers to carry out hair inspections and conduct awareness programmes within the Ministry of Health. Collaboration with the Ministry of Education as well as municipalities to share resources and implement these programmes to increase awareness and educate teachers, parents and the children themselves on the importance of good standards of personal hygiene could significantly reduce the prevalence of pediculosis in this area.

\section{Acknowledgments}

We would like to thank the nurses who helped in the examination and education of the children. Sincere thanks also go the Director of Education of the Mafraq Governorate who gave permission to conduct this study. Finally, we thank all school principals and the parents, teachers and students of the schools that participated in this study for their cooperation.

\section{References}

1. Motovali-Emami M et al. Epidemiological aspects of pediculosis capitis and treatment evaluation in primary school children in Iran. Pakistan Journal of Biological Sciences, 2008, 11:260-264.

2. Hodjati M, Mousavi N, Mousavi M. Head lice infestation in school children of a low socio-economic area of Tabriz City, Iran. African Journal of Biotechnology, 2008,7(13):22922294 http://www.academicjournals.org/AJB/PDF/ pdf2008/4Jul/Hodjati\%20et\%20al.pdf, accessed 18 October 2011).

3. Gratz NG. Human lice: their prevalence, control and resistance to insecticides; a review 1985-1997.Geneva, World Health Organization, 1997.
4. Burgress FI. Head louse developing a practical approach. Practitioner, 1998, 242:126-129.

5. Nazari M, Fakoorziba MR, Shobeiri F. Pediculosis capitis infestation according to social factors in Hamedan, Iran. Southeast Asian Journal of Tropical Medicine and Public Health, 2006, 37:95-98.

6. Bailey AM, Prociv P. Persistent head lice following multiple treatments: Evidence for insecticide resistance in pediculus humanus capitis. Australian Journal of Dermatology, 2000, 41:250-254.

7. Shakkoury WA, Abu-Wandy E. Prevalence of skin diseases among primary school children in Amman, Jordan. Eastern Mediterranean Health Journal, 1999, 5:955-959. 
8. Amr ZS, Nusier MN. Pediculosis capitis in northern Jordan. International Journal of Dermatology, 2000, 39:919-921.

9. Bahamdan K, Mahfour AA, Tallab T. Skin diseases among adolescent boys in Abha, Saudi Arabia. International Journal of Dermatology, 1996, 35:405-407.

10. Al-Shawa RM. Head louse infestations in Gaza governorates. Journal of Medical Entomology, 2006, 43:505-507.

11. Kokturk A et al. The prevalence of pediculosis capitis in schoolchildren in Mersin, Turkey. International Journal of Dermatology, 2003, 42:694-698.

12. Ozcelik S, Degerli S, Aslan A. [Investigation of the prevalence of Pediculus in Alahaci village primary school students in the Sivas province]. Acta Parasitologica Turcica, 2006, 30:184-186 [In Turkish].

13. Downs AM et al. Factors that may be influencing the prevalence of head lice in British school children. Paediatric Dermatology, 2000, 17:72-74.

14. Catala S, Junco L, Vaporaky R. Pediculus capitis infestation according to sex and social factors in Argentina. Revista de Saude Publica, 2005, 39:438-443.

15. Bachok $\mathrm{N}$ et al. Prevalence and associated factors of head lice infestation among primary schoolchildren in Kelantan, Malaysia. Southeast Asian Journal of Tropical Medicine and Public Health, 2006, 37:536-543.

16. El-Basheir ZM, Fouad MA. A preliminary pilot survey on lice pediculosis in Sharkia Governorate and treatment of lice with natural plant extracts. Journal of the Egyptian Society of Parasitology, 2002, 32:725-736.

17. Atambay $\mathrm{M}$ et al. [The frequency of intestinal parasites and head lice among students of the Aksemsettin Primary School for Deaf Students]. Acta Parasitologica Turcica, 2007, 3:62-65 [In Turkish].
18. Al-Saeed WY et al. Prevalence and pattern of skin disorders among female schoolchildren in Eastern Saudi Arabia. Saudi Medical Journal, 2006, 27:227-234.

19. Counahan $\mathrm{M}$ et al. Head lice prevalence in primary schools in Victoria, Australia. Journal of Paediatric and Child Health, 2004, 40(11):616-619.

20. Speare R, Buettner PG. Head lice in pupils of a primary school in Australia and implications for control. International Journal of Dermatology, 1999, 38:285-290.

21. Sim S et al. A survey on head lice infestation in Korea (2001) and the therapeutic efficacy of oral trimethoprim/sulfamethoxazole adding to lindane shampoo. Korean Journal of Parasitology, 2003, 41:57-61.

22. Kamiabi F, Nakhaei FH. Prevalence of pediculosis capitis and determination of risk factors in primary-school children in Kerman. Eastern Mediterranean Health Journal, 2005, 11(56):988-992.

23. Menan E et al. Pediculose du cuir chevelu en milieu scolaire dans la ville d'Abidjan: prevalence et influence des conditions socio-economiques [Scalp pediculosis in school environment in the city of Abidjan: prevalence and influence of socioeconomic conditions]. Santé (Montrouge, France), 1999, 9:32-37.

24. Willems $S$ et al. The importance of socioeconomic status and individual characteristics on the prevalence of head lice children. European Journal of Dermatology, 2005,15(5):387-392

25. Mumcuoglu KY, Miller J. The relevance of head louse comb and nits to head louse infestations. Trends in Entomology, 2003, 3:113-117.

26. Heukelbach J, Feldmeier $\mathrm{H}$.Ectoparasites - the underestimated realm. Lancet, 2004, 363(9412):889-891. 